\section{Evaluation of Drought Tolerance in Arkansas Cowpea Lines at Seedling Stage}

\author{
Qirui Cui and Haizheng Xiong \\ Department of Horticulture, PTSC 316, University of Arkansas, Fayetteville, \\ AR 72701
}

\section{Yufeng Yufeng}

Department of Horticulture, PTSC 316, University of Arkansas, Fayetteville, AR 72701; and Cereal Crop Institute, Henan Academy of Agricultural Sciences, Zhengzhou, 450002, China

\author{
Stephen Eaton \\ Vegetable Research Station, University of Arkansas, 3810 Thornhill Street, \\ Alma, AR 72921
}

\section{Sora Imamura, Jossie Santamaria, and Waltram Ravelombola \\ Department of Horticulture, PTSC 316, University of Arkansas, Fayetteville, AR 72701}

Richard Esten Mason, Lisa Wood, and Leandro Angel Mozzoni
Department of Crop Soil and Environmental Science, Fayetteville, AR 72701

Ainong Shi

Department of Horticulture, PTSC 316, University of Arkansas, Fayetteville, AR 72701

Additional index words. breeding-line screening, cowpea, chlorophyll content, lodging, plant healthiness

\begin{abstract}
Cowpea [Vigna unguiculate (L.) Walp.] is not only a healthy, nutritious, and versatile leguminous crop; it also has a relatively high adaptation to drought. Research has shown that cowpea lines have a high tolerance to drought, and many of them can survive more than 40 days under scorching and dry conditions. The cowpea (Southern pea) breeding program at the University of Arkansas has been active for more than 50 years and has produced more than 1000 advanced breeding lines. The purpose of this study was to evaluate the drought-tolerant ability in Arkansas cowpea lines and use the drought-tolerant lines in cowpea production or as parents in cowpea breeding. A total of 36 University of Arkansas breeding lines were used to screen drought tolerance at the seedling stage in this study. The experiment was conducted in the greenhouse using a randomized complete block design (RCBD) with two replicates, organized in a split-plot manner, where the drought treatment (drought and nondrought stress) as the main plot and the cowpea genotypes as the subplot. Drought stress was applied for 4 weeks, and three drought-tolerant-related traits were collected and analyzed. Results showed that cowpea breeding lines: '17-61', '17-86', 'Early Scarlet', and 'ARBlackeye \#1' were found to be drought tolerant.
\end{abstract}

Received for publication 7 Apr. 2020. Accepted for publication 4 May 2020.

Published online 12 June 2020

This work is supported, at least in part, by the U.S. Department of Agriculture (USDA) National Institute of Food and Agriculture Hatch project number ARK0VG2018 and also supported by USDAAgricultural Research Service Project Number: 6046-21000-012-13S with Agreement Number/ FAAIN: 58-6046-9-004.

Q.C. and H.X. are co-first authors and contributed equally to this work.

A.S. is the corresponding author. E-mail: ashi@ uark.edu.

This is an open access article distributed under the CC BY-NC-ND license (https://creativecommons. org/licenses/by-nc-nd/4.0/). adaptation to drought (Hall and Patel, 1985). However, because most cowpeas are grown in the dry, subtropic area, drought is still one of the significant abiotic constraints for cowpea production. In some drier places in Niger, the average yield is nearly 20 times less than the average yield in the United States, where water is abundant (Agbicodo et al., 2009).

Research has shown that there is a considerable difference among cowpea varieties in drought tolerance (Mai-Kodomi et al., 1999). Many cowpea breeding programs have been created to breed drought-tolerant cowpea varieties, and some cowpea cultivars were proven to be drought tolerant. For example, the cowpea cultivars Machakos 66 and Katumani 80, released by the Kenya National program, are drought-resistant varieties. Early-maturing varieties are also developed to avoid many late-stage biotic and abiotic constraints, including drought (Ehlers and Hall, 1997); however, research showed that these varieties were vulnerable to midseason drought (Thiaw et al., 1993).

Many studies show that cowpea has a strong ability to tolerate drought in the vegetative stage; however, cowpea drought tolerance at the seedling stage has not gained much attention (Muchero et al., 2008). Because vegetative-stage drought-tolerant cowpea has been extensively studied, it is crucial to explore more seedling-stage drought-tolerant cowpea lines for future researchers to study more about the seedling stage drought-tolerant mechanism and genes in the genome of cowpea. In a water stress test, although most of the cowpea seedlings were stunted, many of them survived for $43 \mathrm{~d}$ under very hot and dry conditions and recovered after they were irrigated (Hall, 2012). Various studies also found that the cultivars that showed seedling stage drought tolerance had a big chance to survive the whole life circle in the drought stress environment with a reasonable level of yield (Hall, 2012; Muchero et al., 2013; Singh et al., 1999). Because of the strong ability of cowpea to tolerate drought, and its relatively small genome size (about $620 \mathrm{Mb}$ ) (Arumuganathan and Earle, 1991), cowpea can be an "ideal model to study the molecular mechanisms of drought tolerance in crops" (Agbicodo et al., 2010).

The varieties with strong drought tolerance would maintain a higher photosynthetic rate under drought conditions (Reddy et al., 2004). There are two main aspects of this identification: adaptability in crop morphology and anatomy; and the adaptability of physiological and biochemical reactions, and plants. The commonly used identification indicators include morphological indicators, growth and development indicators, and physiological and biochemical indicators.

The cowpea (Southern pea) breeding program at the University of Arkansas has been active for more than 50 years and has produced more than 1000 advanced breeding lines and released more than 12 varieties (Brar et al., 1999). The varieties have been used by the processing industry and are widely grown by producers for fresh-market. The program has developed a diversity of 


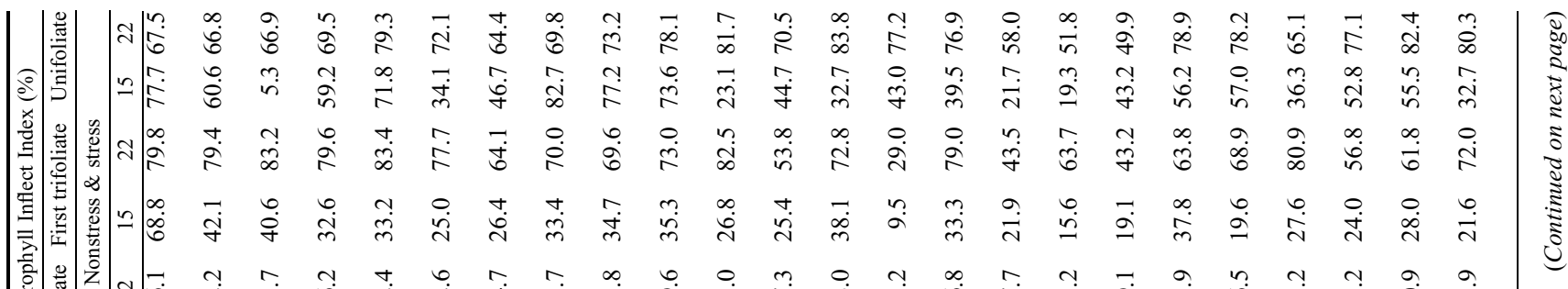
竘

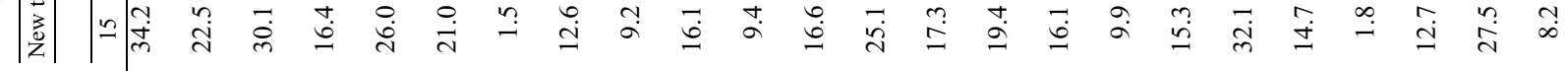

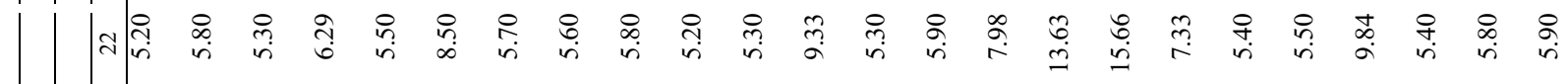

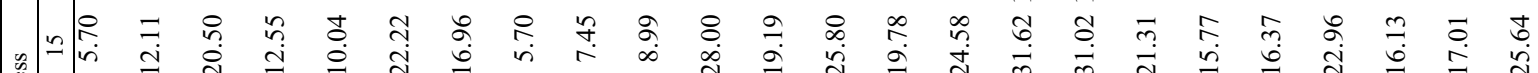

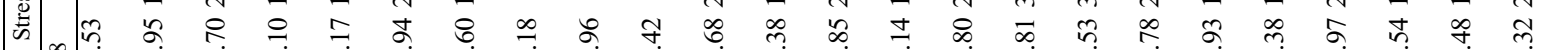

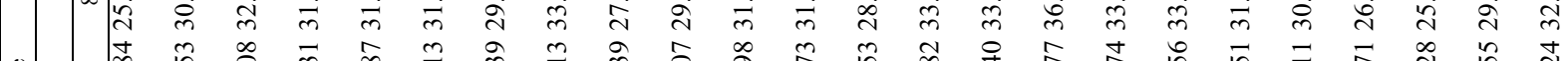

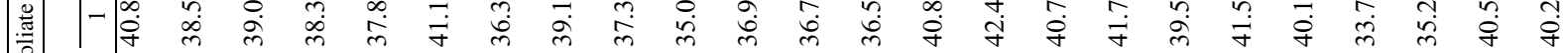

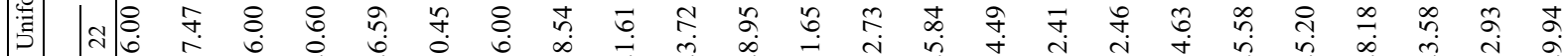

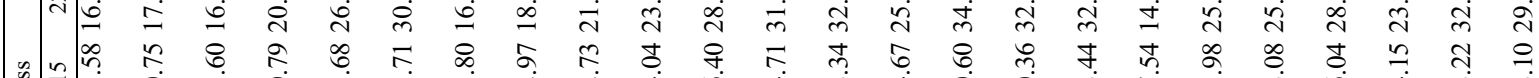

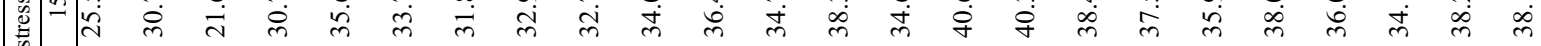

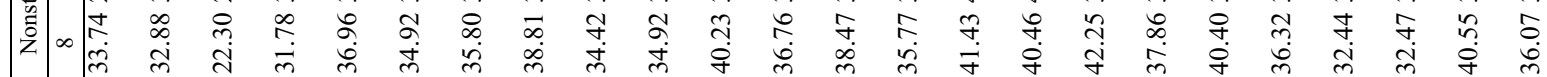

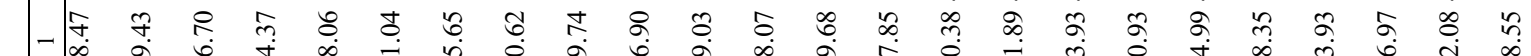

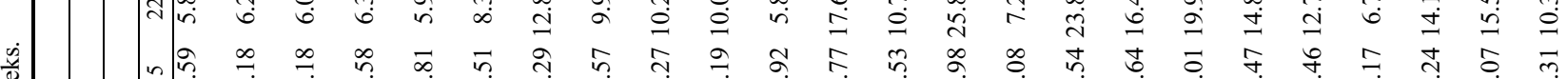

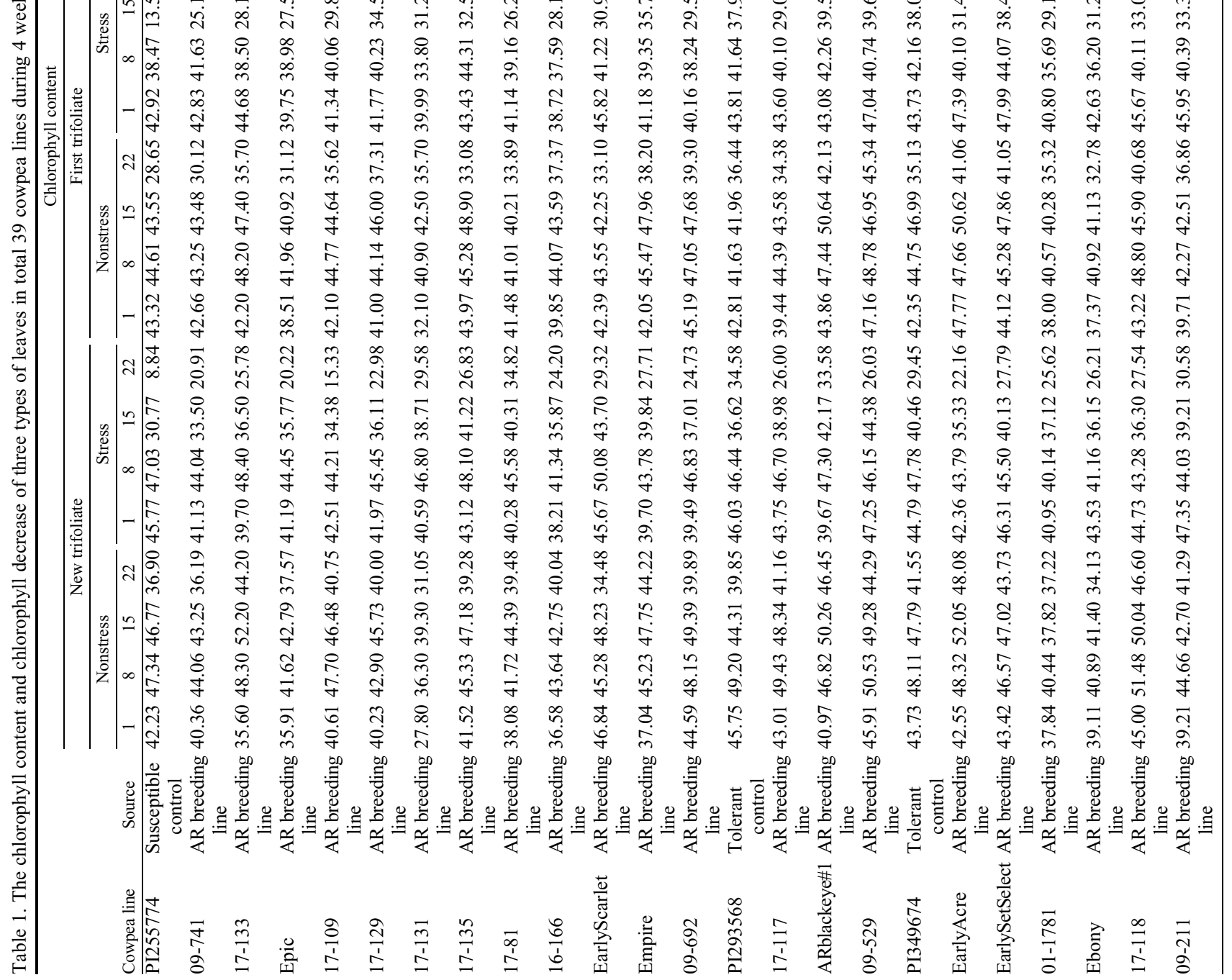




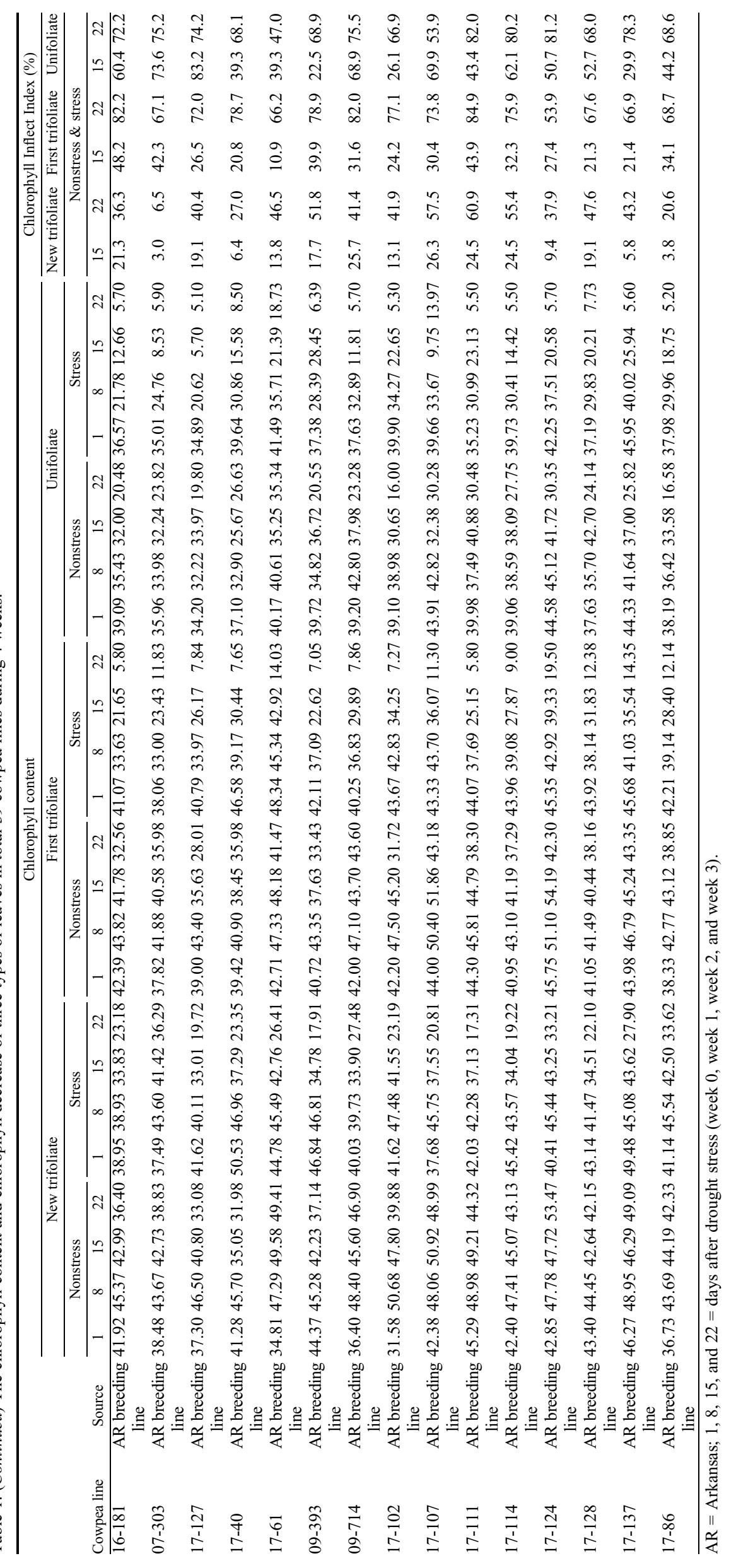


cowpea types with a range of mature seed patterns and colors, including blackeye, pinkeye, and red holstein, and various seedcoat colors, including black, brown, green, cream, and yellow. However, the seedling stage drought-tolerance ability of that group of cowpea lines remains unknown. The purpose of this study was to evaluate the drought-tolerant ability in Arkansas cowpea lines to use drought tolerance in cowpea breeding. The specific research objectives of this research are to evaluate drought tolerance in cowpea lines at the seedling stage under greenhouse conditions.

\section{Materials and Methods}

Plant material. A total of 36 Arkansas cowpea lines were used in this study for drought-tolerance evaluation. Also, two previous reported drought-tolerant lines 'PI293568' and 'PI349674', and one drought-susceptible line, 'PI255774' (Ravelombola et al., 2018) were used as controls (Table 1).

Greenhouse evaluation for drought tolerance. The indoor evaluation was carried out in the greenhouse at the Arkansas Agricultural Research and Extension Center, Fayetteville, AR. During the experiment, the day/night temperatures in the greenhouse was maintained at $25^{\circ} \mathrm{C} / 20^{\circ} \mathrm{C}$. The screening method was similar to the "Wooden Box" screening methodology established by Singh et al. (1999) and Verbree et al. (2015) with minor modifications (Ravelombola et al., 2018). All cowpea lines were planted in Sterilite polypropylene boxes (Sterilite Corporation, Townsend, MA; dimensions $88.6 \mathrm{~cm} \times 42.2 \mathrm{~cm} \times 15.6 \mathrm{~cm}$ ) that were filled with Sunshine Mix \#1 Natural \& Organic (Agawan, MA) up to $10.5 \mathrm{~cm}$ high; $6 \mathrm{~L}$ of tap water was added into each box $2 \mathrm{~d}$ before planting to make sure that the potting mix was at its field capacity stage when seeds were planted.

The experimental design was an RCBD with two replicates per genotype, organized in a split-plot manner, with the drought treatment as the main plot and the cowpea genotypes as the subplot. For each replicate, the 39 cowpea lines ( 36 tested lines plus three controls) were planted with a total of eight boxes, where four boxes were used as the control with watering without drought stress, and the other four boxes as the treatment group with drought stress (Fig. 1).

For each box, a total of ten $7.5-\mathrm{cm}$ spaced rows were designed across the box length. Each testing cowpea line was planted within each row. A total of six uniform and vigorous plants were kept at each row when the first trifoliate leaf began to expand. Fertilizer (Miracle-Gro, Detroit, MI) was applied 1 week after the emergence of cowpea seed from the medium. For each row in every box, $150 \mathrm{~mL}$ of tap water was irrigated every $3 \mathrm{~d}$ until the first trifoliate leaf was fully developed. Drought stress was imposed for the stress treatment by stopping water irrigation when the first trifoliate was utterly expanded, and water stress lasted for 4 weeks (week 0 to week 3 ) until some cowpea genotypes were utterly dead, indicating susceptibility to drought stress. The control (unstress of drought) treatment was irrigated with 150 $\mathrm{mL}$ of tap water every $3 \mathrm{~d}$ continuously.

Measurements. Three drought-related traits, chlorophyll content in trifoliate and unifoliate leaves, overall plant healthiness, and the main stem lodging, were measured from the 39 cowpea lines

Leaf chlorophyll content was measured using the SPAD-502 Plus Chlorophyll Meter (Spectrum Technologies, Inc., Plainfield, IL). For each plant, three types of leaves: unifoliate (U), first trifoliate $(\mathrm{T})$, and new (second) trifoliate (NT) were measured separately (Fig. 2). Measurements were taken weekly after drought stress was imposed. For each leaflet of the unifoliate or trifoliate, measurements were taken three times to avoid edge effect, and the average of the three measurements was kept as the final chlorophyll content value. To evaluate the drought tolerance in each cowpea line by chlorophyll content change, the parameters Chlorophyll Inflect Index (González, 1996), was estimated using the following formulas: Chlorophyll absolute decrease (CD) $=\mathrm{CC}-\mathrm{CS}$; Chlorophyll Inflect Index $(\mathrm{CII})=100 \% * \mathrm{CD} /(\mathrm{CC})$, where $\mathrm{CC}=$ chlorophyll content for control, and $\mathrm{CS}=$ chlorophyll content for drought stress.

The overall plant's healthiness scores were measured using a 1 to 5 scale $(1=$ plant completely green, $2=$ new trifoliate completely green with chlorotic unifoliate and trifoliate, $3=$ new trifoliate is chlorotic, $4=$ severe signs of necrosis on all leaves with a green growing tip, and $5=$ dead plants) (Fig. 3). Overall plant healthiness was measured twice per plant basis in the third and fourth week after first applying drought stress. To reduce the error in the statistical analysis, we converted the score value into a percentage for calculation. The "Healthiness" value was calculated as follows: $100 \%$ * (5-Overall plant healthiness score-1)/4. To

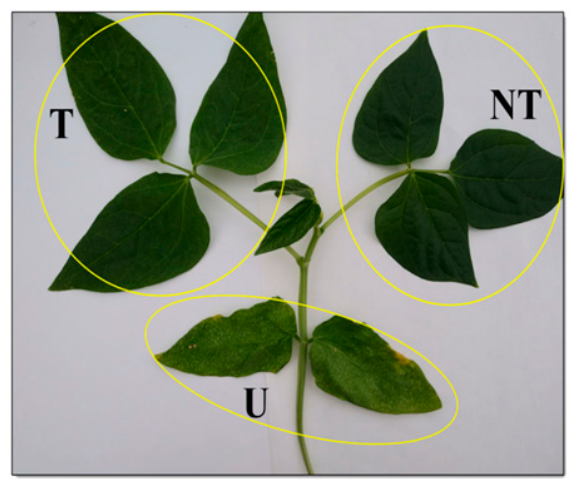

Fig. 2. Three types of leaf for chlorophyll content $\mathrm{U}=$ unifoliate leaf; $\mathrm{T}=$ first trifoliate leaf; $\mathrm{NT}=$ new trifoliate leaf.
(B)

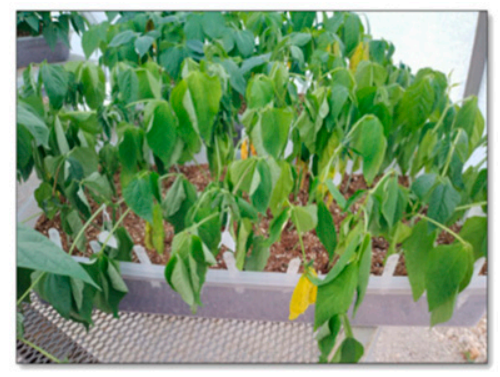

(C)
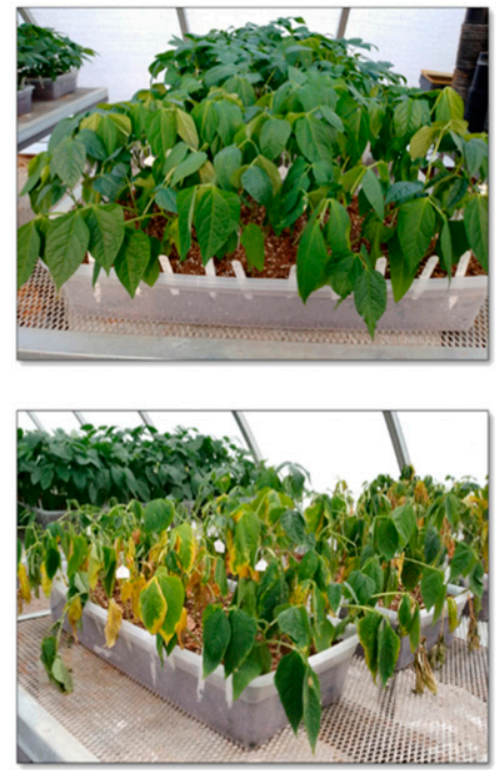

(D)

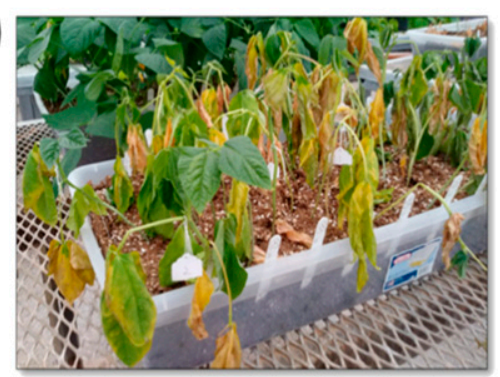

Fig. 1. Greenhouse phenotyping experiments for cowpea drought tolerance: drought stress was applied for (A) 1, (B) 8, (C) 15, and (D) $22 \mathrm{~d}$.

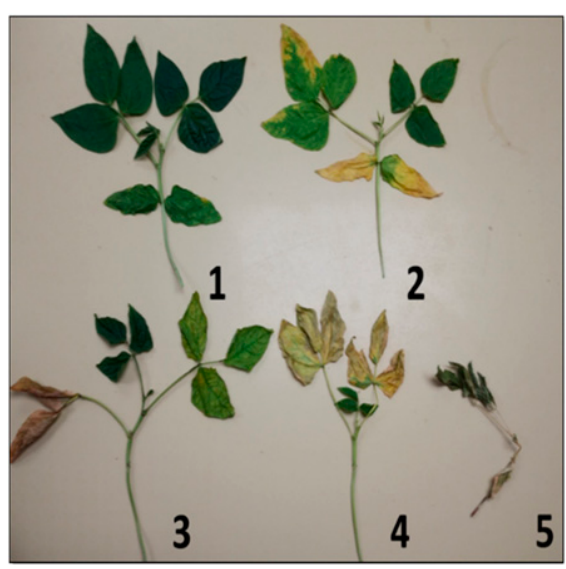

Fig. 3. Overall plant healthiness assessed on a 1 to 5 scale: $1=$ green $(100 \%$ health $), 2=$ green new trifoliate with chlorotic unifoliate and first trifoliate ( $75 \%$ health), 3 = chlorotic new trifoliate with necrotic unifoliate and first trifoliate ( $50 \%$ health), $4=$ severe signs of necrotic on all $5=$ dead plants $(0 \%$ health $)$. leaves, with a green growing tip (25\% health), 
see how healthiness changed over weeks, the parameter of Healthiness Inflect Index (HII) was used with the following formulas: Healthiness absolute decrease (HD) $=\mathrm{HC}-$ $\mathrm{HS}$; $\mathrm{HII}=100 \% * \mathrm{HD} /(\mathrm{HC})$, where $\mathrm{HC}=$
Healthiness for control, and HS = Healthiness for drought stress.

The main stem lodging scores were measured using a 1 to 3 scale $(1=$ vigorous, green main stem, 2 = mildly wilting and light green

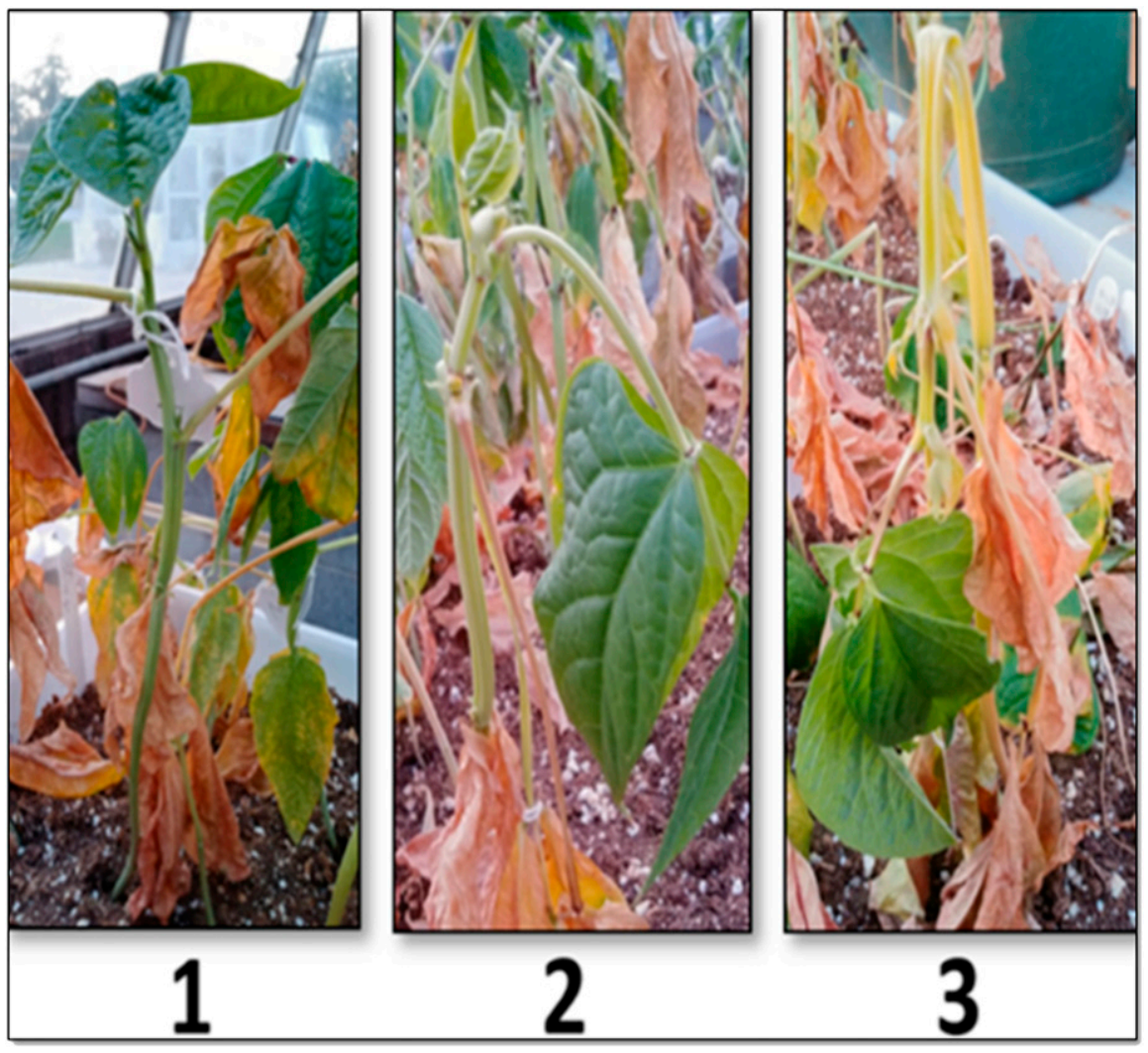

Fig. 4. Plant main stem lodging score assessed on a 1 to 3 scale: $1=$ vigorous, green main stem $(0 \%$ lodging); 2 mildly wilting, light green main stem (50\% lodging); $3=$ completely lodged, yellow main stem (100\% lodging). main stem, and $3=$ completely lodged and yellow main stem) (Fig. 4). The main stem lodging score was assessed on a per-plant basis in the fourth week after the drought stress was initiated. The "Lodging" value was calculated as follows: Lodging $=100 \%$ * (3-Overall plant lodging score-1)/2. To estimate how the lodging increased over weeks, the parameter "Lodging Inflect Index" (LII) was used with the following formulas: Lodging absolute increase (LI) $=\mathrm{LS}-\mathrm{LC}$; LII $=$ $100 \% * \mathrm{LI} /(1-\mathrm{LC})$, where LC = Lodging for control, LS = Lodging for drought stress.

Phenotypic data analysis. The cowpea drought-tolerant data were analyzed using analysis of variance (ANOVA) with the general linear models procedure of JMP Genomics 9 (SAS Institute, Cary, NC). The distribution of the data was drawn using "Distribution," and the scatter plot matrix graphs for chlorophyll content were generated by JMP Genomics 9 (SAS Institute). The broad-sense heritability $\left(\mathrm{H}^{2}\right)$ was estimated using the following formula:

$$
\begin{aligned}
& H^{2}=100 *\left(\sigma_{G}^{2} / \sigma_{P}^{2}\right) \\
& =100 *\left(\frac{\sigma_{G}^{2}}{\sigma_{G}^{2}+\sigma_{e}^{2}}\right),
\end{aligned}
$$

where $\sigma_{P}^{2}$ is phenotypic variance, $\sigma_{G}^{2}$ is genotypic variance, and $\sigma_{e}^{2}$ is variance associated with the experimental error; $\sigma_{G}^{2}$ and $\sigma_{e}^{2}$ were obtained using the following formula:

$$
\begin{aligned}
\sigma_{\mathrm{G}}^{2} & =(\text { MSG-MSE }) / n 0 ; \\
\mathrm{n} 0 & =(\text { observations } / \text { blocks in the study }) \\
\sigma_{e}^{2} & =\text { MSE. }
\end{aligned}
$$

Canonical discriminant analysis and drought tolerance index. To fully assess drought tolerance, we need to standardize
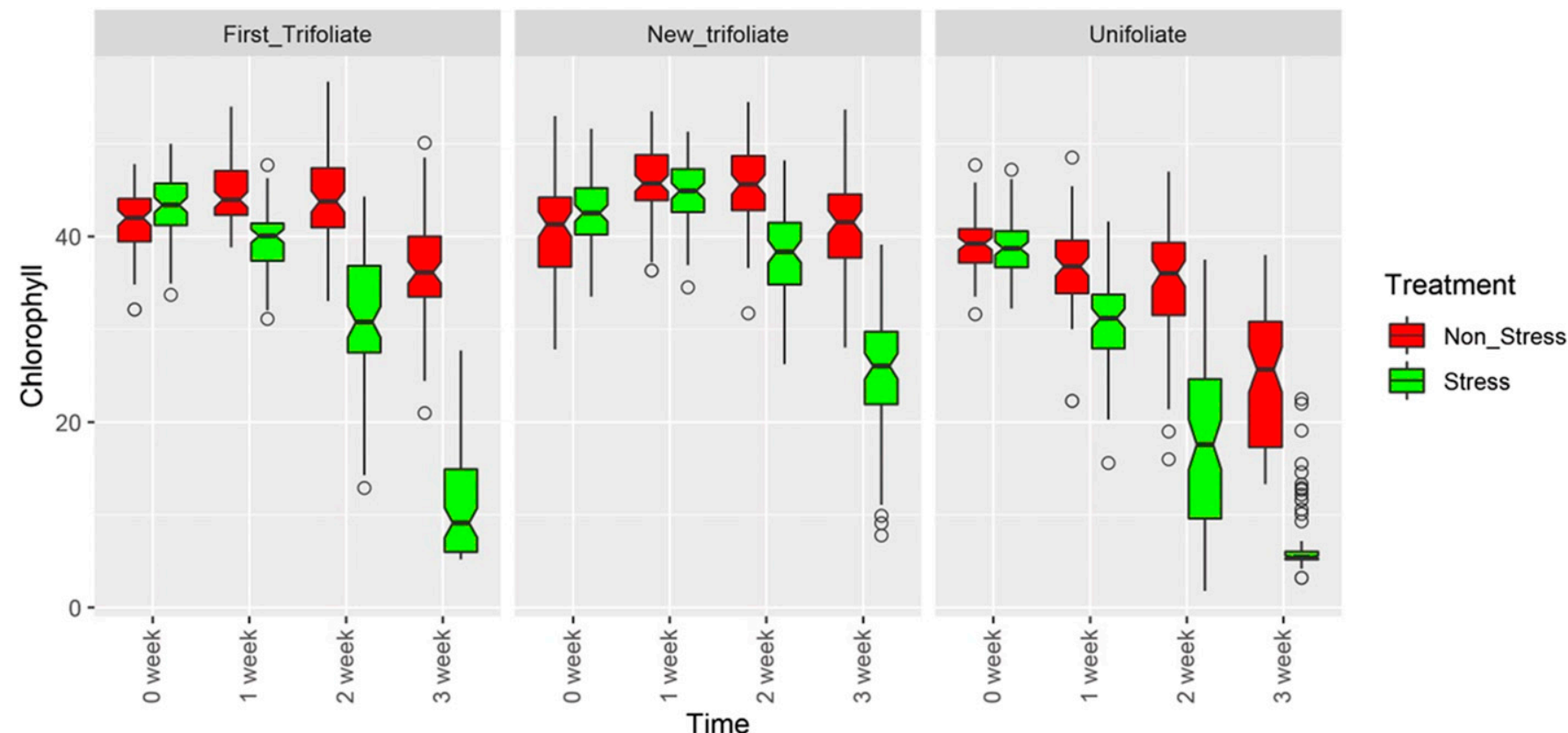

Fig. 5. Chlorophyll content change of unifoliate, trifoliate, new trifoliate under drought stress (green plot) and nonstress (red plot) in 4 weeks. 


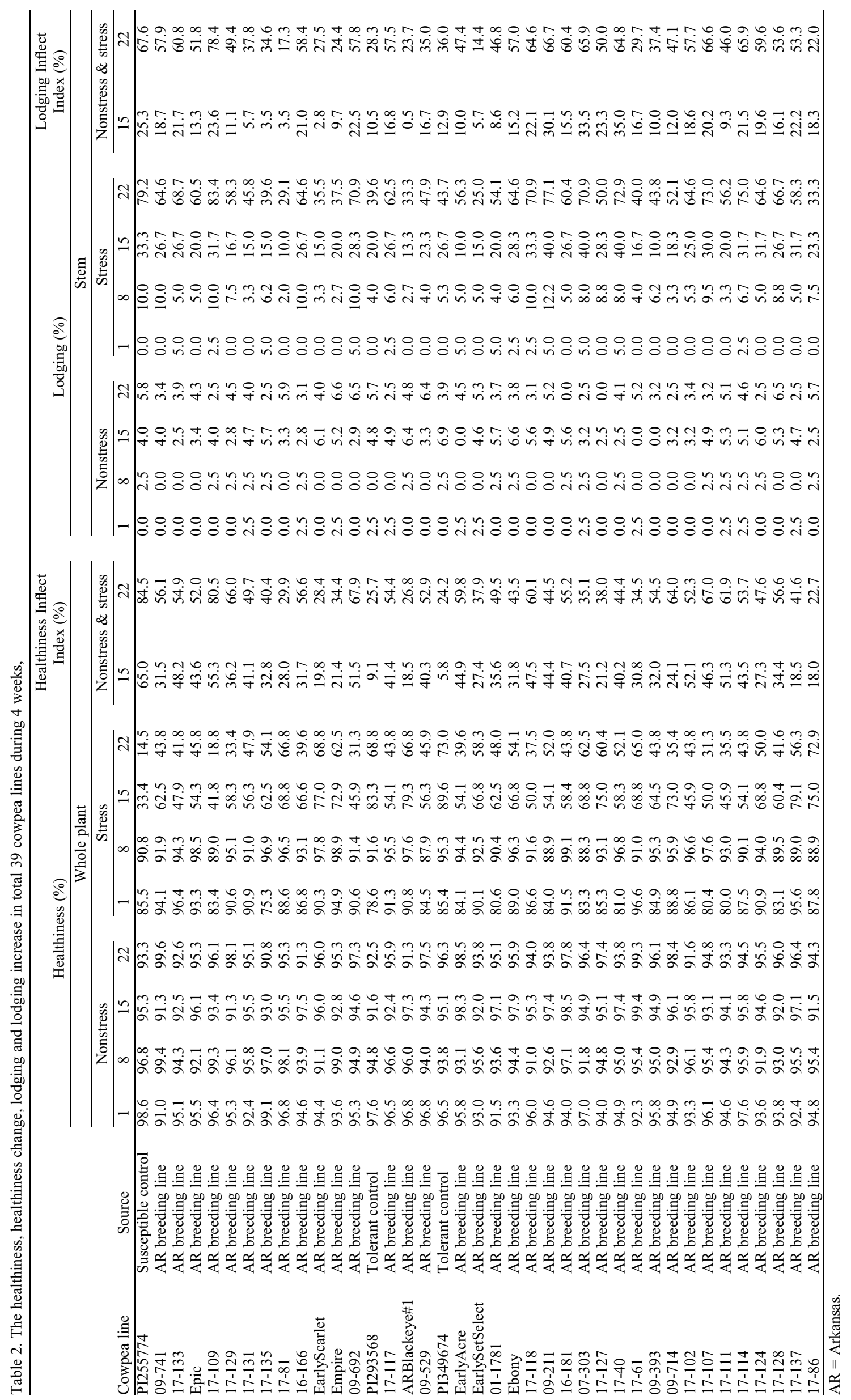

HortScience Vol. 55(7) July 2020 
three indicators (lodging increase, chlorophyll decrease, and healthiness change) before the final evaluation. The same evaluation weight was used to evaluate the change of chlorophyll content in three types of leaf (unifoliate, first trifoliate, and new trifoliate), and this value was finally evaluated comprehensively. In this study, we used two methods to assess the drought tolerance of each line: 1) canonical discriminant analysis was conducted by JMP 13.0 to draw the scatter distribution for 39 lines based on context parameters; and 2) all breeding lines were scored by their orders in three drought-tolerance parameters one by one, according to the tolerance from small to large (the most tolerance line shall be scored as 1 and most susceptible as 39). Then we added three scores for each line, respectively, to comprehensively evaluate drought tolerance.

\section{Results}

Chlorophyll content in trifoliate and unifoliate leaves. The drought stress was imposed for 4 weeks (25 Mar. to $22 \mathrm{Apr}$.), and chlorophyll content difference started to show from the second week (1 Apr. to 8 Apr.). Across the 39 cowpea lines, all three types of leaf (unifoliate, first trifoliate, and new trifoliate) had a significant chlorophyll content drop during the last 2 weeks with drought stress. Overall, unifoliate and first trifoliate chlorophyll contents dropped more than new trifoliate over time; few cowpea lines managed to remain their new trifoliate chlorophyll at the higher level. During the first 2 weeks, the average chlorophyll increased slightly, after that, the chlorophyll contents decreased sharply with drought stress (Fig. 5). Finally, the average chlorophyll content in unifoliate, first trifoliate, and new trifoliate dropped from 38.6 to $7.0,43.4$ to 11.2 , and 40.7 to 25.5 , respectively. The chlorophyll contents of unifoliate, first trifoliate, and new trifoliate after 4-week drought stress varied from 5.4 to $22.5,5.2$ to 27.2 , and 7.8 to 39.1 , respectively. Six cowpea lines: '17-81' (34.8), 'PI293568' (34.6 droughttolerant control), 'ARBlackeye\#1' (33.6), '07-303' (36.3), '17-124' (33.2), and '1786 ' (33.6) have the highest new trifoliate chlorophyll content (Table 1).

The CII indicates how much the chlorophyll content of that cowpea plant leaf has changed (as percentage) in the drought stress condition compared with the same genotype, healthy cowpea plant in control without drought stress but watering. The higher the CII indicates more chlorophyll content lost compared with the healthy plant (i.e., the higher the CII value, the more susceptible the cowpea line is). The CII value for most cowpea lines started to rise significantly in 2 weeks after the drought stress was imposed. At the end of the fourth week, the CII of unifoliate, first trifoliate, and new trifoliate value for each cowpea line varied from 47.0 to $83.8,29.0$ to 84.9 , and 4.7 to 76.1 , respectively. Among the 39 cowpea lines, 'PI349674', '17-109', and '17-111' had the highest CII value, indicating their inability to keep their chlorophyll content stable in the drought stress and showing that their susceptibility to drought stress condition. On the other hand, six cowpea lines, 'PI349674', 'ARBlackeye\#1', '09-529', 'PI293568', '17131 ', and '17-61' had relatively low CII values, indicating that the six lines were drought tolerant (Table 1).

Overall plant healthiness. Overall plant healthiness scores were recorded in 4 weeks after the drought stress treatment. The plants without stress had an excellent growth con- dition, whereas the healthiness of stressed plants dropped rapidly in the last 2 weeks (Fig. 6). For week 2, the over plant healthiness varied from 25.0 to 91.8 , with an average of 61.8 and an SD of 14.4. For week 3 , the plant healthiness score varied from 8.3 to 79.3 , with an average of 48.6 and an SD of 16.1 (Table 2). The plant healthiness change was generated using the last 2 weeks of data. The higher value percentage meant more healthiness the plant had kept in the drought stress condition, suggesting the cowpea line was drought tolerant. The healthiness change

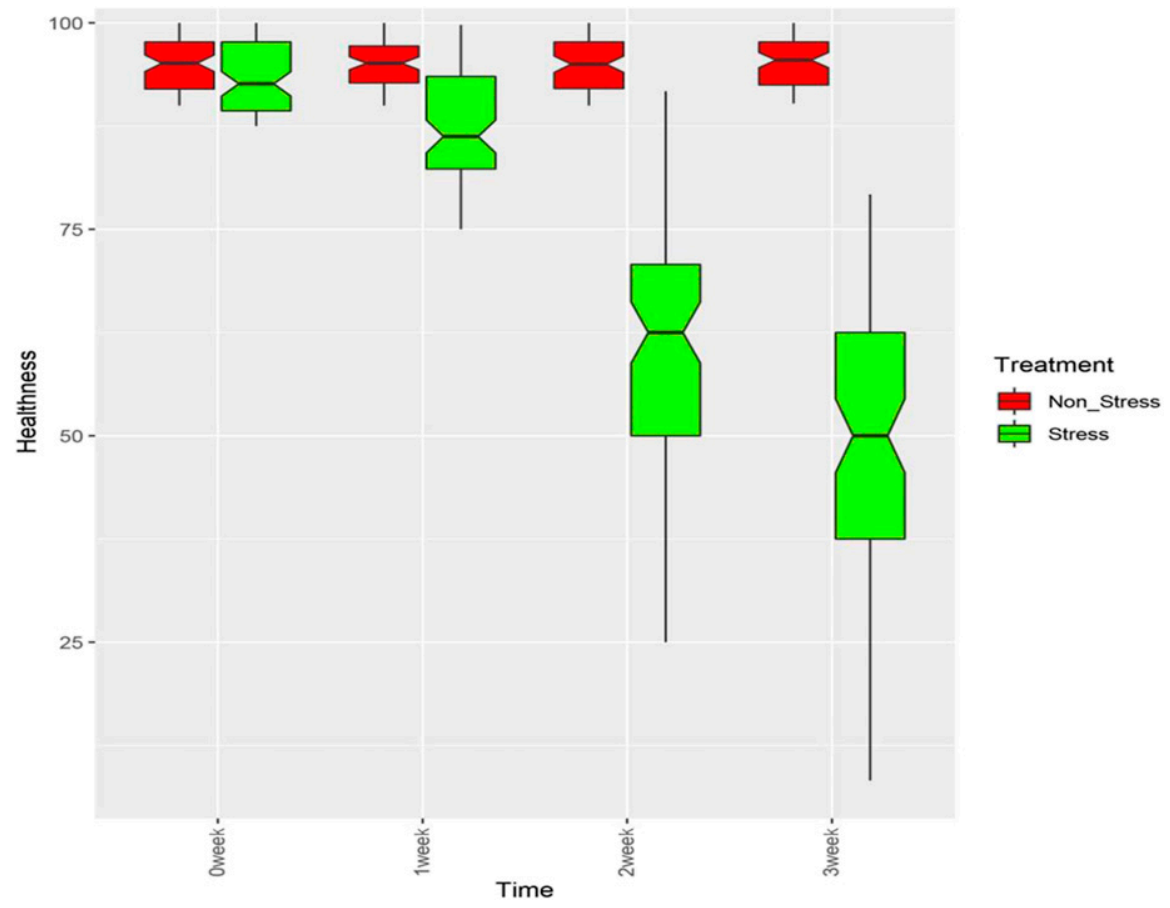

Fig. 6. Healthiness change of plant under drought stress (green plot) and nonstress (red plot) in 4 weeks.

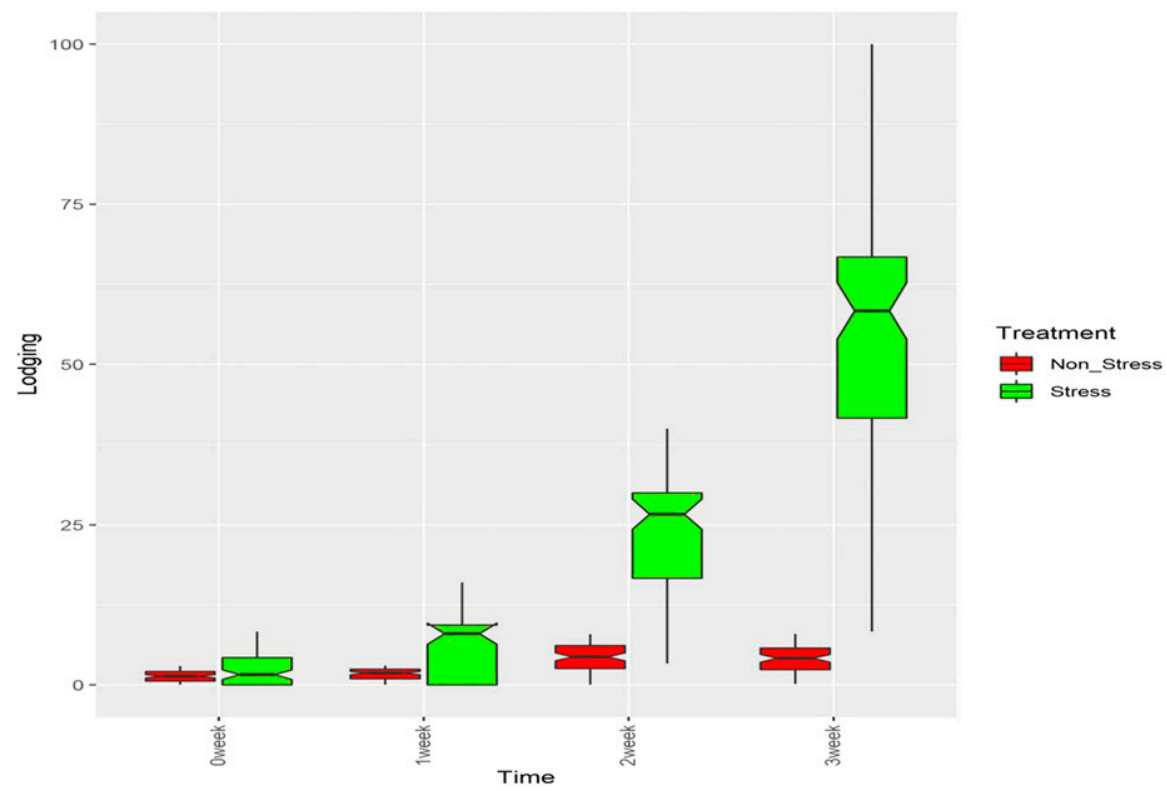

Fig. 7. Lodging change of plant under drought stress (green plot) and nonstress (red plot) in 4 weeks. 
Table 3. Analysis of variance for chlorophyll content, stem lodging, and plant healthiness.

\begin{tabular}{|c|c|c|c|c|c|c|c|c|c|}
\hline Trait & Stress & Description & Time & Source & DF & Sum of squares & Mean square & $\mathrm{F}$ ratio & Prob $>F$ \\
\hline \multirow[t]{72}{*}{ Chlorophyll content } & Nonstress & New trifoliate & 1 & Model & 38 & $1,340.87$ & 35.29 & 1.4279 & 0.1363 \\
\hline & & & & Error & 39 & 963.79 & 14.71 & & \\
\hline & & & & C. Total & 77 & $2,304.66$ & & & \\
\hline & & & 8 & Model & 38 & 758.80 & 19.97 & 1.8874 & 0.0258 \\
\hline & & & & Error & 39 & 412.61 & 10.58 & & \\
\hline & & & & C. Total & 77 & $1,171.41$ & & & \\
\hline & & & 15 & Model & 38 & $1,149.13$ & 30.24 & 2.5423 & 0.0023 \\
\hline & & & & Error & 39 & 463.91 & 11.90 & & \\
\hline & & & & C. Total & 77 & $1,613.04$ & & & \\
\hline & & & 22 & Model & 38 & $2,018.10$ & 53.11 & 4.6896 & 0.0000 \\
\hline & & & & Error & 39 & 441.66 & 11.32 & & \\
\hline & & & & C. Total & 77 & $2,459.76$ & & & \\
\hline & & First trifoliate & 1 & Model & 38 & 654.40 & 17.22 & 3.2985 & 0.0002 \\
\hline & & & & Error & 39 & 203.61 & 5.22 & & \\
\hline & & & & C. Total & 77 & 858.01 & & & \\
\hline & & & 8 & Model & 38 & 596.43 & 15.70 & 1.8002 & 0.0357 \\
\hline & & & & Error & 39 & 340.03 & 8.72 & & \\
\hline & & & & C. Total & 77 & 936.46 & & & \\
\hline & & & 15 & Model & 38 & $1,226.52$ & 32.28 & 3.1197 & 0.0003 \\
\hline & & & & Error & 39 & 403.50 & 10.35 & & \\
\hline & & & & C. Total & 77 & $1,630.02$ & & & \\
\hline & & & 22 & Model & 38 & $1,391.64$ & 36.62 & 1.2428 & 0.2511 \\
\hline & & & & Error & 39 & $1,149.23$ & 29.47 & & \\
\hline & & & & C. Total & 77 & $2,540.87$ & & & \\
\hline & & Unifoliate & 1 & Model & 38 & 581.83 & 15.31 & 5.4567 & 0.0000 \\
\hline & & & & Error & 39 & 109.43 & 2.81 & & \\
\hline & & & & C. Total & 77 & 691.27 & & & \\
\hline & & & 8 & Model & 38 & $1,327.38$ & 34.93 & 4.7569 & 0.0000 \\
\hline & & & & Error & 39 & 286.39 & 7.34 & & \\
\hline & & & & C. Total & 77 & $1,613.76$ & & & \\
\hline & & & 15 & Model & 38 & $1,746.21$ & 45.95 & 1.5087 & 0.1028 \\
\hline & & & & Error & 39 & $1,187.91$ & 30.46 & & \\
\hline & & & & C. Total & 77 & $2,934.12$ & & & \\
\hline & & & 22 & Model & 38 & $2,726.10$ & 71.74 & 2.5187 & 0.0025 \\
\hline & & & & Error & 39 & $1,110.84$ & 28.48 & & \\
\hline & & & & C. Total & 77 & $3,836.94$ & & & \\
\hline & Stress & New trifoliate & 1 & Model & 38 & 783.87 & 20.63 & 2.1257 & 0.0106 \\
\hline & & & & Error & 39 & 378.47 & 9.70 & & \\
\hline & & & & C. Total & 77 & $1,162.34$ & & & \\
\hline & & & 8 & Model & 38 & 527.05 & 13.87 & 1.3347 & 0.1867 \\
\hline & & & & Error & 39 & 405.28 & 10.39 & & \\
\hline & & & & C. Total & 77 & 932.33 & & & \\
\hline & & & 15 & Model & 38 & 932.67 & 24.54 & 1.0480 & 0.4420 \\
\hline & & & & Error & 39 & 913.38 & 23.42 & & \\
\hline & & & & C. Total & 77 & $1,846.05$ & & & \\
\hline & & & 22 & Model & 38 & $2,545.54$ & 66.99 & 2.5124 & 0.0026 \\
\hline & & & & Error & 39 & $1,039.85$ & 26.66 & & \\
\hline & & & & C. Total & 77 & $3,585.39$ & & & \\
\hline & & First trifoliate & 1 & Model & 38 & 497.42 & 13.09 & 1.4832 & 0.1125 \\
\hline & & & & Error & 39 & 344.19 & 8.83 & & \\
\hline & & & & C. Total & 77 & 841.61 & & & \\
\hline & & & 8 & Model & 38 & 686.37 & 18.06 & 2.6017 & 0.0019 \\
\hline & & & & Error & 39 & 270.76 & 6.94 & & \\
\hline & & & & C. Total & 77 & 957.13 & & & \\
\hline & & & 15 & Model & 38 & $2,611.25$ & 68.72 & 2.9432 & 0.0006 \\
\hline & & & & Error & 39 & 910.57 & 23.35 & & \\
\hline & & & & C. Total & 77 & $3,521.82$ & & & \\
\hline & & & 22 & Model & 38 & $1,979.01$ & 52.08 & 2.6909 & 0.0014 \\
\hline & & & & Error & 39 & 754.81 & 19.35 & & \\
\hline & & & & C. Total & 77 & $2,733.82$ & & & \\
\hline & & Unifoliate & 1 & Model & 38 & 511.59 & 13.46 & 2.0860 & 0.0123 \\
\hline & & & & Error & 39 & 251.71 & 6.45 & & \\
\hline & & & & C. Total & 77 & 763.30 & & & \\
\hline & & & 8 & Model & 38 & $1,154.52$ & 30.38 & 2.4925 & 0.0028 \\
\hline & & & & Error & 39 & 475.38 & 12.19 & & \\
\hline & & & & C. Total & 77 & $1,629.90$ & & & \\
\hline & & & 15 & Model & 38 & $3,924.63$ & 103.28 & 1.6160 & 0.0701 \\
\hline & & & & Error & 39 & $2,492.59$ & 63.91 & & \\
\hline & & & & C. Total & 77 & $6,417.22$ & & & \\
\hline & & & 22 & Model & 38 & 784.27 & 20.64 & 2.5472 & 0.0023 \\
\hline & & & & Error & 39 & 316.00 & 8.10 & & \\
\hline & & & & C. Total & 77 & $1,100.27$ & & & \\
\hline
\end{tabular}


Table 3. (Continued) Analysis of variance for chlorophyll content, stem lodging, and plant healthiness.

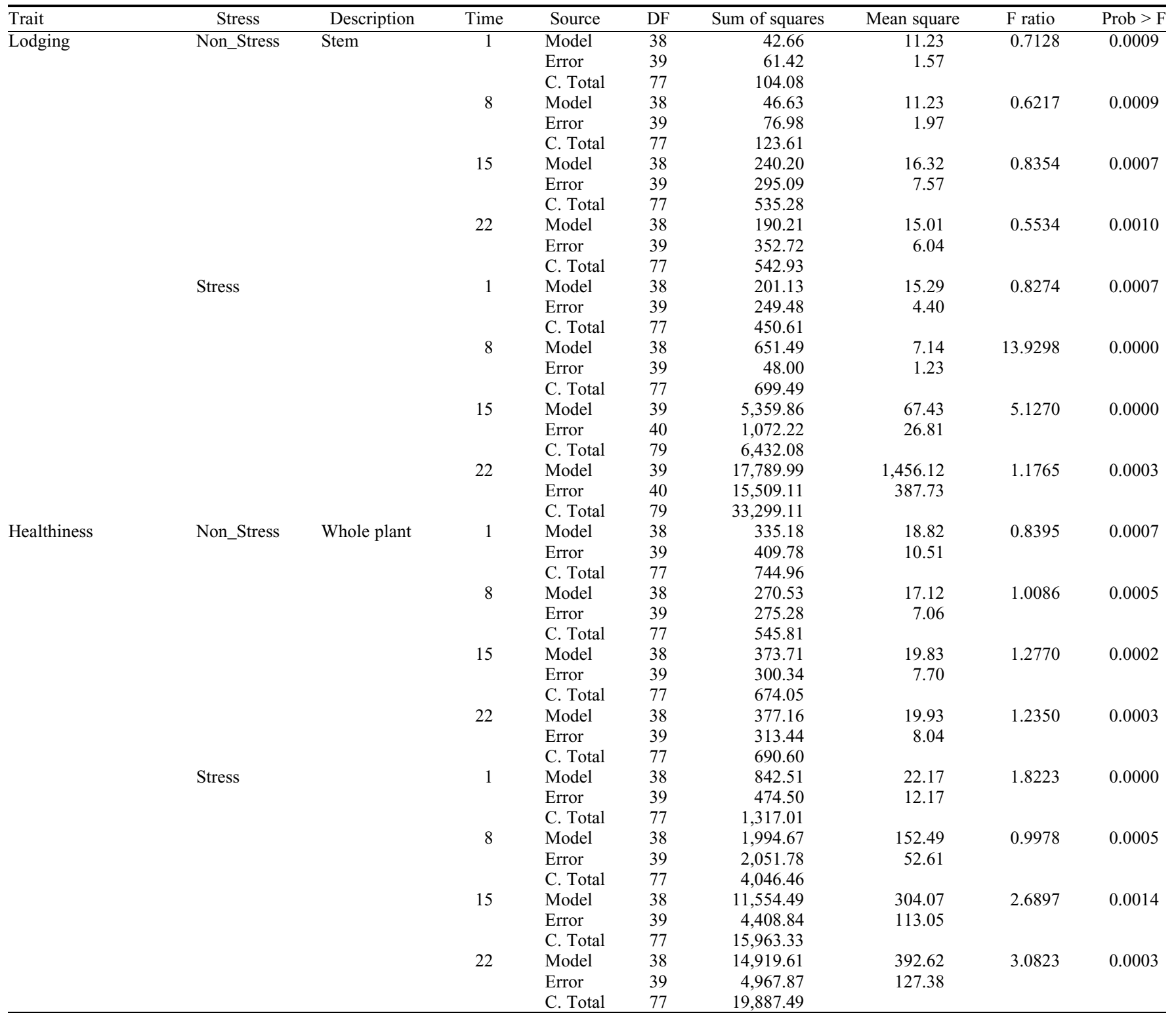

$1,8,15$, and $22=$ days after drought stress (week 0 , week 1 , week 2 , and week 3 ). C. Total = total count.

Table 4. Broad-sense heritability of chlorophyll content, stem lodging, and plant healthiness,

\begin{tabular}{lllr}
\hline Trait & Treatment & Description & $\mathrm{H}^{2}(\%)$ \\
\hline Chlorophyll Content & Nonstress & New trifoliate & 61.17 \\
& & First trifoliate & 50.40 \\
& & Unifoliate & 63.67 \\
& Stress & New trifoliate & 35.70 \\
& & First trifoliate & 55.75 \\
Lodging & & Unifoliate & 52.70 \\
& Nonstress & Stem & 70.44 \\
Healthiness & Stress & Whole plant & 71.91 \\
& Nonstress & & 55.94 \\
& Stress & & 73.17 \\
\hline
\end{tabular}

percentage varied from $17.4 \%$ to $91.6 \%$ with an average of $48.9 \%$. Based on the healthiness changes, three cowpea lines, 'PI255774', '17111 ', and ' $17-109$ ' had the lowest healthiness change, indicating their susceptibility to drought stress. The six lines 'PI349674', 'ARBlackeye\#1', '09-529', '17-131', 'PI293568', and
'17-61' had the most significant healthiness change, indicating that the six lines were drought tolerant.

Plant main stem lodging scores. Plant main stem lodging scores were recorded on the 4 weeks after drought stress. The stressed plants in the first 2 weeks were all growing erectly, whereas the lodging of plants was increased rapidly in the last 2 weeks (Fig. 7). The main stem lodging scores varied from $14.5 \%$ to $100 \%$, with an average of $58.4 \%$ and an SD of 20.5 (Table 2, Supplemental Table 1). Among the 39 cowpea lines, three cowpea lines, '17-118', '16-181', and '17127 ' had a stem lodging of $100 \%$, indicating that the three lines were most susceptible to drought stress. On the other hand, six cowpea lines, 'PI349674', '17-61', 'EarlyScarlet', '17135 ', '17-86', and 'ARBlackeye\#1' had a very low stem lodging score, indicating that the five lines were drought tolerant.

ANOVA, broad-sense heritability, and correlation. We conducted the ANOVA, broad-sense heritability, and correlation analysis for chlorophyll content, stem lodging, and healthiness. According to the ANOVA and broad-sense heritability, the variations of drought-tolerant parameters are most (60\% to 
$84 \%$ ) caused by different breeding lines but not by the repeats (Table 3 ). These results indicate that the tolerance parameters and varieties we chose in this experiment have higher discrimination and heritability, respectively. The heritability of three parameters was calculated by ANOVA, and most of them were in high-level weather with or without the stress: lodging and healthiness had $\approx 70 \%$, and chlorophyll content had $\approx 35 \%$ to $64 \%$ (Table 4 ). Correlation analysis showed that those drought-tolerant traits had high positive correlations between each other
(Table 5). Chlorophyll decrease and healthiness decrease has $\approx 15 \%$ to $67 \%$ correlation; chlorophyll decrease and stem lodging have at least $\approx 15 \%$ to $38 \%$ correlation; stem lodging and healthiness have $36 \%$ and $87 \%$ correlation in week 2 and week 3 , respectively.

Canonical discriminant analysis and drought-tolerance index. Principal component analysis based on drought tolerance parameters was conducted for canonical discriminant. The scatter plot showed that the 39 breeding lines were classified into three groups. The drought-tolerance lines 'PI349674', 'ARBlackeye\#1', '17-86', 'PI293568', '1761 ', and 'EarlyScarlet' were grouped on the left side with green color, whereas the susceptible lines '17-114', '16-181', '17-118', '17109', '17-111', and 'PI255774' were in the opposite with blue color. This result indicated significant differences in drought resistance between breeding lines (Fig. 8).

Taking three drought-tolerance parameters into consideration, we assumed that they had equal weights, then pulsed the scores together to get cowpea comprehensive

Table 5. Correlation analysis for chlorophyll decrease, stem lodging increase, and healthiness change.

\begin{tabular}{|c|c|c|c|c|c|c|c|c|c|}
\hline & CIIT15 (\%) & CIINT15 (\%) & CIIU22 (\%) & CIIT22 (\%) & CIINT22 (\%) & HII22 (\%) & HII15 (\%) & LII22 (\%) & LII15 (\%) \\
\hline CIIU15 & 31.66 & 10.56 & 17.64 & 17.21 & 12.30 & 25.32 & 18.77 & 21.82 & 15.61 \\
\hline CIINT15 & & & 19.67 & 21.06 & 60.15 & 44.92 & 37.77 & 26.77 & 20.70 \\
\hline CIIU22 & & & & 22.82 & 7.84 & 20.50 & 15.02 & 38.47 & 20.62 \\
\hline CIINT22 & & & & & & 67.43 & 53.44 & 37.86 & 32.46 \\
\hline HII22 & & & & & & & 78.35 & 53.77 & 37.97 \\
\hline HII15 & & & & & & & & 47.33 & 36.26 \\
\hline
\end{tabular}

$\mathrm{CII}=$ Chlorophyll Inflect Index; T = first trifoliate leaf; 15 and $22=$ days after drought stress (week 2 and week 3); NT = new trifoliate leaf; $\mathrm{U}=$ unifoliate leaf; $\mathrm{HII}=$ Healthiness Inflect Index; LII = Lodging Inflect Index.

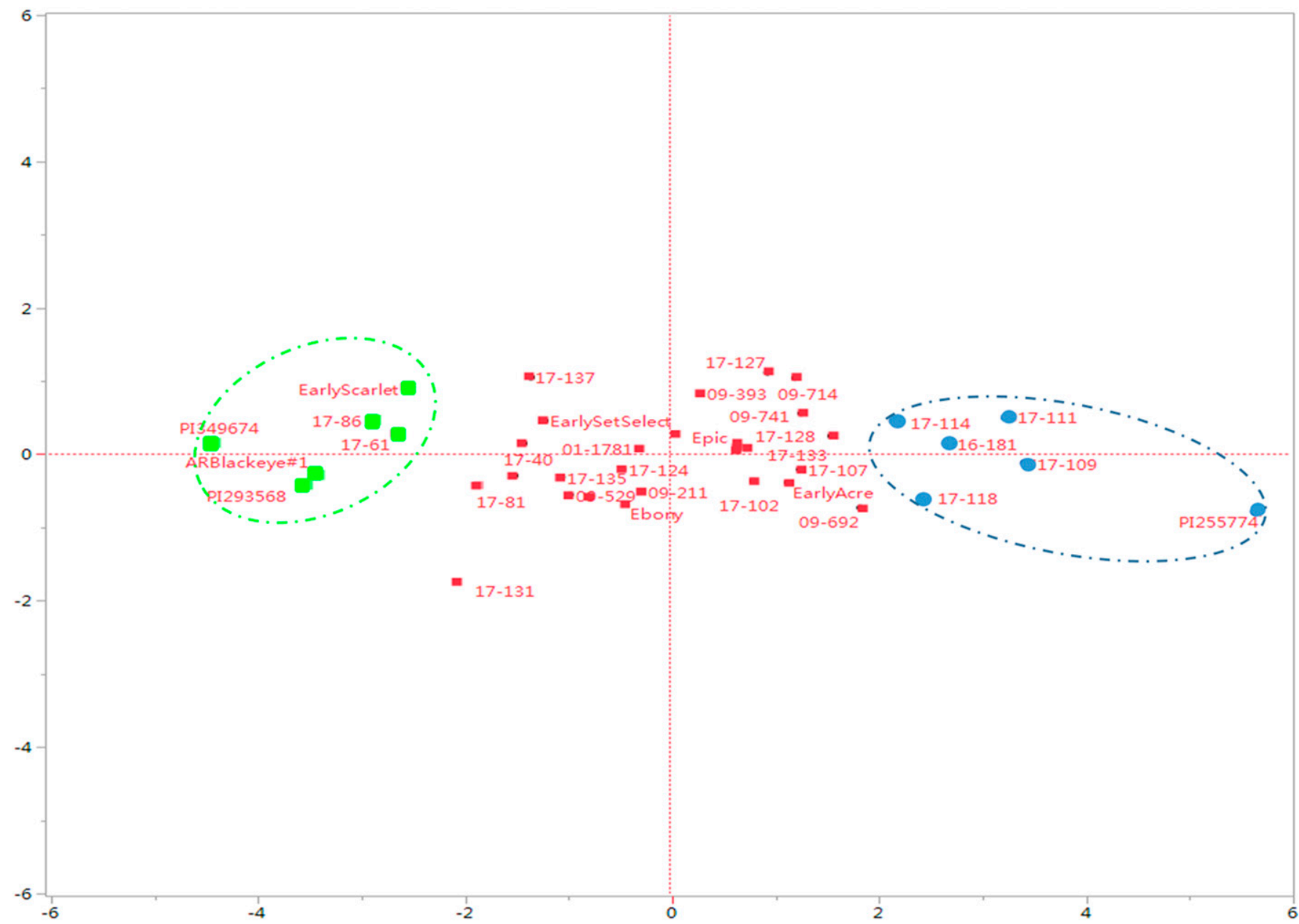

Fig. 8. Canonical discriminant analysis for 39 lines by three drought indexes: drought-tolerance $=$ green; drought-susceptible $=$ blue; medium-tolerance $/$ susceptible $=$ red. 
drought tolerance indexes and then sorted them in Table 6. Six lines, 'PI349674', 'ARBlackeye\#1', '17-86', 'PI293568', 'EarlyScarlet', and '17-61' were evaluated as high tolerance of drought (scored less than 30 in green circle), whereas six lines ' 17 114', '16-181', '17-118', '17-109', '17-111', and 'PI255774' were assessed as susceptible varieties (scored more than 95 in blue circle). It is worth mentioning that the highest scored line was the susceptible control we used in this experiment. This result was very consistent with the canonical discriminant analysis.

\section{Discussion}

Drought tolerance of crops is interacted by a variety of factors and each factor may play a decisive role in tolerance, so the research on drought tolerance is complicated. There are differences in the mechanisms of drought tolerance of crops in different environments, different crop varieties, and different growth stages of the same variety. Therefore, more and more attention has been paid to the comprehensive index method. The comprehensive index method is to use several indicators for comprehensive evaluation of crop drought tolerance, which can make up for the limitations and shortcomings of single-indicator drought tolerance evaluation, and the evaluation results are closer to the actual situation.

Three drought-tolerance parameters. Plants carry out photosynthesis in the chloroplasts. The first step of photosynthesis is the transformation of light energy into chemical energy by chlorophyll. The content of chlorophyll directly affects the photosynthetic rate (Arjenaki et al., 2012; Nikolaeva et al., 2010). Drought and water shortage can cause chloroplast damage, such as decreased chlorophyll content, ultrastructural damage of chloroplast, decreased enzymatic activity required for the dark reaction, and blocked transport of photosynthetic products, which can accumulate in leaves and cannot be transported to grains, resulting in a traffic jam in leaves (Munné-Bosch et al., 2001). By analyzing the chlorophyll content data in three different types of the leaves over 4 weeks of drought stress, we found that both unifoliate and first trifoliate chlorophyll content dropped to a very low level (chlorophyll content lower than 10) at the end of week 4. The new trifoliate chlorophyll content also

Table 6. Overall ranking of drought tolerance for 39 cowpea breeding lines.

\begin{tabular}{|c|c|c|c|c|c|}
\hline Cowpea lines & $\begin{array}{l}\text { Chlorophyll } \\
\text { score }\end{array}$ & $\begin{array}{l}\text { Healthiness } \\
\text { score }\end{array}$ & $\begin{array}{l}\text { Lodging } \\
\text { score }\end{array}$ & $\begin{array}{c}\text { Tolerant } \\
\text { index }\end{array}$ & Rank \\
\hline PI349674 & 1 & 1 & 1 & 3 & 1 \\
\hline ARBlackeye\#1 & 2 & 4 & 6 & 12 & 2 \\
\hline $17-86$ & 7 & 3 & 5 & 15 & 3 \\
\hline PI293568 & 5 & 2 & 12 & 19 & 4 \\
\hline $17-61$ & 6 & 12 & 2 & 20 & 5 \\
\hline EarlyScarlet & 13 & 5 & 3 & 21 & 6 \\
\hline $17-131$ & 4 & 24 & 7 & 35 & 7 \\
\hline $17-81$ & 19 & 7 & 9 & 35 & 8 \\
\hline $17-40$ & 8 & 16 & 11 & 35 & 9 \\
\hline Empire & 10 & 6 & 20 & 36 & 10 \\
\hline $17-137$ & 11 & 9 & 19 & 39 & 11 \\
\hline $17-135$ & 24 & 13 & 4 & 41 & 12 \\
\hline EarlySetSelect & 20 & 11 & 13 & 44 & 13 \\
\hline $09-529$ & 3 & 25 & 22 & 50 & 14 \\
\hline $09-393$ & 22 & 18 & 15 & 55 & 15 \\
\hline $07-303$ & 17 & 10 & 29 & 56 & 16 \\
\hline $01-1781$ & 9 & 17 & 30 & 56 & 17 \\
\hline $17-124$ & 16 & 14 & 27 & 57 & 18 \\
\hline $17-129$ & 21 & 30 & 8 & 59 & 19 \\
\hline Ebony & 12 & 15 & 35 & 62 & 20 \\
\hline $09-211$ & 15 & 22 & 26 & 63 & 21 \\
\hline $17-117$ & 25 & 26 & 17 & 68 & 22 \\
\hline Epic & 26 & 27 & 16 & 69 & 23 \\
\hline $16-166$ & 30 & 21 & 18 & 69 & 24 \\
\hline $17-128$ & 18 & 23 & 33 & 74 & 25 \\
\hline $09-741$ & 32 & 19 & 24 & 75 & 26 \\
\hline $17-127$ & 28 & 8 & 39 & 75 & 27 \\
\hline EarlyAcre & 34 & 32 & 10 & 76 & 28 \\
\hline $09-714$ & 35 & 20 & 21 & 76 & 29 \\
\hline $17-107$ & 27 & 36 & 14 & 77 & 30 \\
\hline $17-102$ & 14 & 33 & 31 & 78 & 31 \\
\hline $17-133$ & 23 & 31 & 25 & 79 & 32 \\
\hline 09-692 & 29 & 37 & 23 & 89 & 33 \\
\hline $17-114$ & 36 & 29 & 32 & 97 & 34 \\
\hline $16-181$ & 33 & 28 & 38 & 99 & 35 \\
\hline $17-118$ & 31 & 34 & 37 & 102 & 36 \\
\hline $17-109$ & 38 & 38 & 28 & 104 & 37 \\
\hline $17-111$ & 37 & 35 & 34 & 106 & 38 \\
\hline PI255774 & 39 & 39 & 36 & 114 & 39 \\
\hline
\end{tabular}

The score is the ordinal of drought-tolerance parameter among all breeding line. The drought-tolerant index is the sum of three parameters.

dropped significantly, but the magnitude was not as dramatic as the unifoliate and trifoliate. We also found that some cowpea lines were capable of keeping the new trifoliate chlorophyll content level, which suggested that new trifoliate chlorophyll content and its related parameters (Li et al., 2006), inflect index, can be a good trait to measure for the droughttolerant assessment. Among the 39 cowpea lines, huge differences were also found in both overall plant healthiness score and plant main stem lodging score, indicating that both traits can contribute to the overall droughttolerance level for a cowpea line. However, different cowpea lines performed and scored differently based on the trait we measured. Because of the complexity of the droughttolerant trait, it is hard to use only one parameter to decide the overall drought tolerance of a certain line (Mafakheri et al., 2010).

The relative water content of the leaves can reflect the healthiness of plants, and it can also maintain the greenness and habit in the whole plant (Dedio 1975). Under drought conditions, the cultivars with strong drought tolerance had a higher relative water content of leaves to reduce cell damage caused by water loss and maintain the healthy leaf shape structure and function (Siddique et al., 2000). In the external morphology of the droughttolerant varieties, the leaf curl degree is low, and the waxy layer is well covered. More studies have shown that the ability of isolated leaves of varieties with strong drought tolerance to retaining water is more durable than that of varieties with weak drought tolerance (Egilla et al., 2005). In this study, we ranked and scored the phenotype of the cowpea leaves by integrating the greenness, structure, curl, and growth of the leaves to evaluate the healthiness of the whole plant in drought stress. Compared with the traditional identification method, which is completely dependent on specific physiological or growth indicators, this method can save time, money, and labor.

Lodging is another parameter of water content in the plant, which can reflect the damage of the drought to plant stem (Kebede et al., 2001). Especially in cowpea breeding, if plants lodged due to water shortage at the seedling stage, the yield of cowpea will still be seriously affected, even if they regain vitality after later irrigation (Rosenow and Clark, 1995). This is why we use lodging as a criterion for drought resistance in this study. However, one issue we need to consider is the weight of this trait, because cowpea has a very high creeping attribute, and many cultivated cowpeas are lodging badly no matter whether it is under drought stress or not. Therefore, the weight of this parameter should be reduced when considering its droughttolerance characteristics comprehensively.

In this experiment, three parameters, chlorophyll decrease (CII), healthiness change (HII), and stem lodging increase (LII), were used as the main parameters for evaluating drought tolerance. The value of these parameters can be well repeated in our experiment 
(Table 6). We assumed all three traits had the same importance value for the overall drought tolerance and used them to rank each cowpea line for its drought tolerance summed the values of the three traits. In the end, an overall ranking score was given to each cowpea line and the overall ranking score from the sum of the three ranking number drought tolerance. The cowpea lines with the low overall ranking score were considered to be overall drought tolerant, and the cowpea lines with higher overall ranking scores were considered to be drought susceptible.

Data collection and analysis. In the process of data acquisition, to ensure that each breeding line has enough seedlings (six plants) in a treatment, we often keep more than six seedlings. While in the process of data collection we recorded all survived seedlings, which may cause a slight difference in the resolution of three parameters among varieties, but did not affect the estimate of the final results. It is important to note that we used the date of stopping water as the starting time of drought treatment, but at that point, especially during the first week of ceasing water (week 0 ), there is no drought stress to the plants. It can also be seen from the results that the significant differences between the stress and the nonstress group occurred only after 2 weeks (week 0 and week 1) of drought stress. In particular, the content of chlorophyll increased in both of the treatments during first 2 weeks of drought stress. Therefore, when calculating and evaluating the chlorophyll decrease (CII), healthiness change (HII), and stem lodging increase (LII), we only used and showed those data from the last 2 weeks, thus reducing the bias and making the conclusion more reliable. We collected all the values of the three parameters during 4 weeks, respectively. Therefore, the following results of calculation and analysis were described carefully in all tables for the purpose of providing readers and researchers with sufficient information for reference. However, in the calculation of heritability, we averaged all values from 4 weeks to one final result, because the discussion of heritability difference in each week is not the point of this article.

Screening drought-tolerant lines. The two previous reported drought-tolerant lines 'PI293568' and 'PI349674', and one droughtsusceptible line, 'PI255774' were also ranked (Table 5). Cowpea line 'PI293568' was ranked as number 4, and 'PI349674' as number 1 in the overall drought-tolerant ranking, indicating their drought tolerance, and 'PI255774' ranked number 39 as the most susceptible to drought tolerance in the study, which showed and confirmed our previous results (Ravelombola et al., 2018). The three cowpea genotypes showed stable tolerance or susceptibility across the three parameters and were used as controls in this study.

Worldwide, drought is increasingly affecting crop production and yields (Singh et al., 1997). The effective way to solve this problem is to cultivate drought-tolerant varieties. It is a wise choice to explore new genetic resources with high water utilization characteristics to improve drought resistance. There are some reports on the drought tolerance of cowpea, but most of them were using limited indexes. In this study, the drought resistance of 39 breeding resources was evaluated, and several cowpea materials with different drought tolerance were screened out through water control treatment at the seedling stage for drought stress. The purpose of this study was to identify the drought-tolerance indexes at the seedling stage, screen the drought tolerance breeding resources, and lay a foundation for drought-tolerance gene mapping and identification.

\section{Literature Cited}

Agbicodo, E.M., C.A. Fatokun, R. Bandyopadhyay, K. Wydra, N.N. Diop, W. Muchero, J.D. Ehlers, P.A. Roberts, T.J. Close, R.G.F. Visser, and C.G. van der Linden. 2010. Identification of markers associated with bacterial blight resistance loci in cowpea [Vigna unguiculata (L.) Walp.]. Euphytica 175(2):215-226.

Agbicodo, E.M., C.A. Fatokun, S. Muranaka, R.G.F. Visser, and C.G. van der Linden. 2009. Breeding drought tolerant cowpea: Constraints, accomplishments, and future prospects. Euphytica 167(3):353-370.

Arjenaki, F.G., R. Jabbari, and A. Morshedi. 2012. Evaluation of drought stress on relative water content, chlorophyll content and mineral elements of wheat (Triticum aestivum L.) varieties. Intl. J. Agr. Crop Sci. 4(11):726-729.

Arumuganathan, K. and E.D. Earle. 1991. Nuclear DNA content of some important plant species. Plant Mol. Biol. Rpt. 9(3):208-218.

Brar, M.S., J.M. Al-Khayri, T.E. Morelock, and E.J. Anderson. 1999. Genotypic response of cowpea Vigna unguiculata (L.) to in vitro regeneration from cotyledon explants. In Vitro Cell. Dev. Biol. Plant 35(1):8-12.

Dedio, W. 1975. Water relations in wheat leaves as screening tests for drought resistance. Can. J. Plant Sci. 55(2):369-378.

Egilla, J.N., F.T. Davies, and T.W. Boutton. 2005 Drought stress influences leaf water content, photosynthesis, and water-use efficiency of Hibiscus rosa-sinensis at three potassium concentrations. Photosynthetica 43(1):135-140.

Ehlers, J.D. and A.E. Hall. 1997. Cowpea (Vigna unguiculata L. walp.). Field Crops Res. 53(1-3): 187-204.

González, L.M. 1996. Use of radioinduction of mutations in obtaining salinity-tolerant rice genotypes. PhD Diss (in Spanish), Granma, Cuba.

Hall, A.E. and P.N. Patel. 1985. Breeding for resistance to drought and heat, p. 137-151. In: Cowpea research, production and utilization. Wiley, New York, NY.

Hall, A. 2012. Phenotyping cowpeas for adaptation to drought. Front. Physiol. 3:155.

Kebede, H., P.K. Subudhi, D.T. Rosenow, and H.T. Nguyen. 2001. Quantitative trait loci influencing drought tolerance in grain sorghum (Sorghum bicolor L. Moench). Theor. Appl. Genet. 103(2-3):266-276.
Li, R., P. Guo, B. Michael, G. Stefania, and C. Salvatore. 2006. Evaluation of chlorophyll content and fluorescence parameters as indicators of drought tolerance in barley. Agr. Sci. China 5(10):751-757.

Mafakheri, A., A.F. Siosemardeh, B. Bahramnejad, P.C. Struik, and Y. Sohrabi. 2010. Effect of drought stress on yield, proline and chlorophyll contents in three chickpea cultivars. Austral. J. Crop Sci. 4(8):580-585.

Mai-Kodomi, Y., B.B. Singh, O. Myers, J.H. Yopp, and P.J. Gibson. 1999. Two mechanisms of drought tolerance in cowpea. <http://www.isgpb.org/ documents/archive/ijgpb-59-3-007.pdf $>$.

Muchero, W., J.D. Ehlers, and P.A. Roberts. 2008. Seedling stage drought-induced phenotypes and drought-responsive genes in diverse cowpea genotypes. Crop Sci. 48(2):541-552.

Muchero, W., P.A. Roberts, N.N. Diop, I. Drabo, N. Cisse, T.J. Close, S. Muranaka, O. Boukar, and J.D. Ehlers. 2013. Genetic architecture of delayed senescence, biomass, and grain yield under drought stress in cowpea. PLoS One 8(7): 70041.

Munné-Bosch, S., T. Jubany-Marí, and L. Alegre. 2001. Drought-induced senescence is characterized by a loss of antioxidant defences in chloroplasts. Plant Cell Environ. 24(12):13191327.

Nikolaeva, M.K., S.N. Maevskaya, A.G. Shugaev, and N.G. Bukhov. 2010. Effect of drought on chlorophyll content and antioxidant enzyme activities in leaves of three wheat cultivars varying in productivity. Russ. J. Plant Physiol. 57(1):87-95.

Ravelombola, W., A. Shi, J. Qin, Y. Weng, G. Bhattarai, B. Zia, W. Zhou, and B. Mou. 2018. Investigation on various aboveground traits to identify drought tolerance in cowpea seedlings. HortScience 53:1757-1765.

Reddy, A.R., K.V. Chaitanya, and M. Vivekanandan. 2004. Drought-induced responses of photosynthesis and antioxidant metabolism in higher plants. J. Plant Physiol. 161(11):11891202.

Rosenow, D.T. and L.E. Clark. 1995. Drought and lodging resistance for a quality sorghum crop. In: Proceedings of the 50th Annual Corn and Sorghum Industry Research Conference, Chicago, 6-7 Dec. 1995, 82-97. (American Seed Trade Association).

Siddique, M.R.B., A.I.M.S. Hamid, and M.S. Islam. 2000. Drought stress effects on water relations of wheat. Bot. Bull. Acad. Sin. 41:35-39.

Singh, B.B., O.L. Chambliss, and B. Sharma. 1997. Recent advances in cowpea breeding, p. 30-49. In: B.B. Singh, D.R. Mohan Raj, K.E. Dashiell, and L.E.N. Jackai (eds.). Advances in Cowpea Research. International Institute of Tropical Agriculture, Ibadan, Nigeria and Japan International.

Singh, B.B., Y. Mai-Kodomi, and T. Terao. 1999. Relative drought tolerance of major rainfed crops of the semi-arid tropics. Indian J. Genet. Plant Breed. 59:437-444

Thiaw, S., A.E. Hall, and D.R. Parker. 1993. Varietal intercropping and the yields and stability of cowpea production in semiarid Senegal. Field Crops Res. 33(3):217-233.

Verbree, M., E. Horlings, P. Groenewegen, I. van der Weijden, and P. van den Besselaar. 2015. Organizational factors influencing scholarly performance: A multivariate study of biomedical research groups. Scientometrics 102(1):25-49. 
Supplemental Table 1. Statistics for chlorophyll content, chlorophyll decrease, lodging, lodging increase, healthiness, and healthiness change.

\begin{tabular}{|c|c|c|c|c|c|c|c|c|c|c|c|c|}
\hline Trait & Treatment & Decription & Date & Mean & $\mathrm{SD}$ & Min & Max & Range & Variance & SE & $\mathrm{CV}$ & Median \\
\hline \multirow[t]{24}{*}{ Chlorophyll content } & \multirow[t]{12}{*}{ Nonstress } & \multirow[t]{4}{*}{ Unifoliate } & 1 & 39.23 & 3.00 & 31.55 & 47.70 & 16.15 & 8.98 & 0.34 & 7.64 & 39.20 \\
\hline & & & 8 & 36.86 & 4.58 & 22.30 & 48.48 & 26.18 & 20.96 & 0.52 & 12.42 & 36.74 \\
\hline & & & 15 & 34.82 & 6.17 & 16.00 & 46.95 & 30.95 & 38.11 & 0.70 & 17.73 & 35.78 \\
\hline & & & 22 & 25.05 & 7.06 & 13.25 & 37.96 & 24.71 & 49.83 & 0.80 & 28.18 & 25.63 \\
\hline & & \multirow[t]{4}{*}{ First trifoliate } & 1 & 41.72 & 3.34 & 32.10 & 47.80 & 15.70 & 11.14 & 0.38 & 8.00 & 41.95 \\
\hline & & & 8 & 44.70 & 3.49 & 38.83 & 54.00 & 15.17 & 12.16 & 0.39 & 7.80 & 43.90 \\
\hline & & & 15 & 44.35 & 4.60 & 33.00 & 56.72 & 23.72 & 21.17 & 0.52 & 10.38 & 43.77 \\
\hline & & & 22 & 36.78 & 5.74 & 21.00 & 50.05 & 29.05 & 33.00 & 0.65 & 15.62 & 36.09 \\
\hline & & \multirow[t]{4}{*}{ New trifoliate } & 1 & 40.50 & 5.47 & 27.80 & 52.97 & 25.17 & 29.93 & 0.62 & 13.51 & 41.28 \\
\hline & & & 8 & 46.06 & 3.90 & 36.30 & 53.53 & 17.23 & 15.21 & 0.44 & 8.47 & 45.70 \\
\hline & & & 15 & 45.64 & 4.58 & 31.70 & 54.52 & 22.82 & 20.95 & 0.52 & 10.03 & 45.60 \\
\hline & & & 22 & 41.17 & 5.65 & 27.97 & 53.65 & 25.68 & 31.94 & 0.64 & 13.73 & 41.55 \\
\hline & \multirow[t]{12}{*}{ Stress } & \multirow[t]{4}{*}{ Unifoliate } & 1 & 38.75 & 3.15 & 32.15 & 47.17 & 15.02 & 9.91 & 0.36 & 8.13 & 38.68 \\
\hline & & & 8 & 30.89 & 4.60 & 15.60 & 41.63 & 26.03 & 21.17 & 0.52 & 14.89 & 31.18 \\
\hline & & & 15 & 17.90 & 9.13 & 1.80 & 37.50 & 35.70 & 83.34 & 1.03 & 51.01 & 17.77 \\
\hline & & & 22 & 7.03 & 3.78 & 5.40 & 22.53 & 17.13 & 14.29 & 0.43 & 53.75 & 5.40 \\
\hline & & \multirow[t]{4}{*}{ First trifoliate } & 1 & 43.20 & 3.31 & 33.70 & 50.00 & 16.30 & 10.93 & 0.37 & 7.65 & 43.40 \\
\hline & & & 8 & 39.45 & 3.53 & 31.08 & 47.67 & 16.58 & 12.43 & 0.40 & 8.94 & 40.06 \\
\hline & & & 15 & 31.02 & 6.76 & 12.92 & 44.30 & 31.38 & 45.74 & 0.77 & 21.80 & 30.77 \\
\hline & & & 22 & 11.23 & 5.96 & 5.20 & 27.70 & 22.50 & 35.50 & 0.67 & 53.05 & 9.14 \\
\hline & & \multirow[t]{4}{*}{ New trifoliate } & 1 & 42.75 & 3.89 & 33.48 & 51.62 & 18.14 & 15.10 & 0.44 & 9.09 & 42.52 \\
\hline & & & 8 & 44.78 & 3.48 & 34.50 & 51.33 & 16.83 & 12.11 & 0.39 & 7.77 & 44.89 \\
\hline & & & 15 & 37.99 & 4.90 & 26.20 & 48.20 & 22.00 & 23.97 & 0.55 & 12.89 & 38.33 \\
\hline & & & 22 & 25.45 & 6.82 & 7.80 & 39.08 & 31.28 & 46.56 & 0.77 & 26.82 & 26.00 \\
\hline \multirow[t]{6}{*}{ Chlorophyll Inflect Index (\%) } & \multirow[t]{6}{*}{ Stress } & \multirow[t]{2}{*}{ Unifoliate } & 15 & 48.33 & 26.82 & 0.30 & 94.34 & 94.04 & 719.26 & 3.04 & 55.49 & 47.34 \\
\hline & & & 22 & 71.23 & 11.42 & 36.80 & 85.57 & 48.78 & 130.46 & 1.29 & 16.04 & 72.19 \\
\hline & & \multirow[t]{2}{*}{ First trifoliate } & 15 & 29.92 & 14.13 & 2.92 & 70.53 & 67.60 & 199.78 & 1.60 & 47.23 & 27.77 \\
\hline & & & 22 & 69.39 & 15.82 & 16.98 & 86.49 & 69.51 & 250.31 & 1.79 & 22.80 & 73.98 \\
\hline & & \multirow[t]{2}{*}{ New trifoliate } & 15 & 16.60 & 11.76 & 0.30 & 48.08 & 47.78 & 138.33 & 1.33 & 70.84 & 14.75 \\
\hline & & & 22 & 37.50 & 17.63 & 0.30 & 81.59 & 81.29 & 310.96 & 2.00 & 47.02 & 37.17 \\
\hline \multirow[t]{8}{*}{ Healthness $(\%)$} & \multirow[t]{4}{*}{ Nonstress } & \multirow[t]{4}{*}{ Whole plant } & 1 & 94.93 & 3.11 & 90.00 & 100.00 & 10.00 & 9.67 & 0.35 & 3.28 & 95.13 \\
\hline & & & 8 & 95.00 & 2.66 & 90.00 & 100.00 & 10.00 & 7.09 & 0.30 & 2.80 & 95.13 \\
\hline & & & 15 & 94.96 & 2.96 & 90.00 & 100.00 & 10.00 & 8.75 & 0.34 & 3.12 & 95.00 \\
\hline & & & 22 & 95.27 & 2.99 & 90.25 & 100.00 & 9.75 & 8.97 & 0.34 & 3.14 & 95.50 \\
\hline & Stress & & 1 & 93.46 & 4.14 & 87.50 & 100.00 & 12.50 & 17.10 & 0.47 & 4.43 & 92.63 \\
\hline & & & 8 & 87.39 & 7.25 & 75.00 & 99.75 & 24.75 & 52.55 & 0.82 & 8.30 & 86.25 \\
\hline & & & 15 & 61.80 & 14.40 & 25.00 & 91.75 & 66.75 & 207.32 & 1.63 & 23.30 & 62.50 \\
\hline & & & 22 & 48.57 & 16.07 & 8.25 & 79.25 & 71.00 & 258.28 & 1.82 & 33.09 & 50.00 \\
\hline Healthness Inflect Index $(\%)$ & Stress & Whole plant & 15 & 34.87 & 15.19 & 5.41 & 74.81 & 69.41 & 2.31 & 1.72 & 43.57 & 33.86 \\
\hline & & & 22 & 48.94 & 16.99 & 17.45 & 91.65 & 74.20 & 2.89 & 1.92 & 34.71 & 48.12 \\
\hline Lodging $(\%)$ & Nonstress & Stem & 1 & 0.76 & 1.16 & 0.00 & 2.95 & 2.95 & 1.35 & 0.13 & 152.72 & 0.00 \\
\hline & & & 8 & 1.09 & 1.27 & 0.00 & 3.00 & 3.00 & 1.61 & 0.14 & 115.85 & 0.00 \\
\hline & & & 15 & 2.20 & 2.64 & 0.00 & 7.62 & 7.62 & 6.95 & 0.30 & 119.69 & 0.00 \\
\hline & & & 22 & 2.79 & 2.66 & 0.00 & 7.94 & 7.94 & 7.05 & 0.30 & 95.07 & 2.50 \\
\hline & Stress & & 1 & 1.58 & 2.39 & 0.00 & 8.33 & 8.33 & 5.74 & 0.27 & 151.66 & 0.00 \\
\hline & & & 8 & 2.12 & 3.00 & 0.00 & 8.33 & 8.33 & 8.97 & 0.33 & 140.95 & 0.00 \\
\hline & & & 15 & 23.88 & 9.02 & 3.33 & 40.00 & 36.67 & 81.42 & 1.01 & 37.79 & 26.67 \\
\hline & & & 22 & 56.43 & 20.53 & 8.33 & 100.00 & 91.67 & 421.51 & 2.30 & 36.39 & 58.33 \\
\hline Lodging Inflect Index(\%) & Stress & Stem & 15 & 22.16 & 9.38 & 3.33 & 40.00 & 36.67 & 87.97 & 1.05 & 42.33 & 23.33 \\
\hline & & & 22 & 58.50 & 23.38 & 5.55 & 100.00 & 94.45 & 546.74 & 2.61 & 39.97 & 64.33 \\
\hline
\end{tabular}

$1,8,15$, and 22 = days after drought stress (week 0 , week 1 , week 2 , and week 3 ). 